\title{
Pentek Metal Coating Removal System: Baseline Report; Greenbook (Chapter)
}

\author{
Topical Report \\ 19980402046 \\ July 31, 1997 \\ Work Performed Under Contract No.: DE-FC21-95MC32260

For

U.S. Department of Energy

Office of Environmental Management

Office of Technology Development

1000 Independence Avenue

Washington, DC 20585
U.S. Department of Energy

Office of Fossil Energy

Federal Energy Technology Center

Morgantown Site

P.O. Box 880

Morgantown, West Virginia 26507-0880

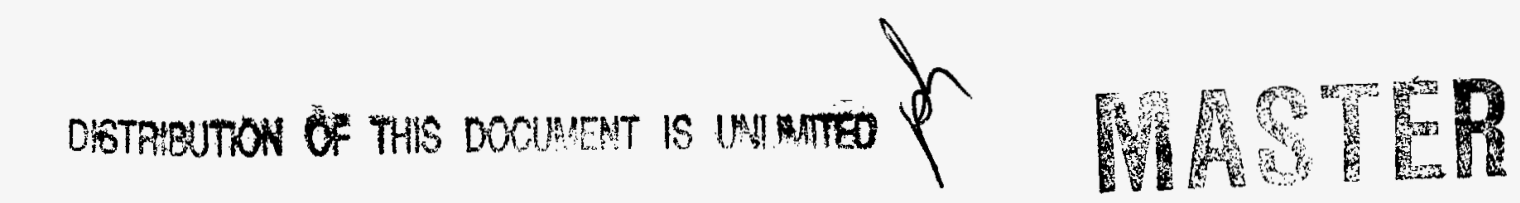

DITC QUALTY TVEYTEUTWD

By

Operating Engineers National Hazmat Program

250 Airport Circle

Beaver, West Virginia 25813 


\section{Disclaimer}

This report was prepared as an account of work sponsored by an agency of the United States Government. Neither the United States Government nor any agency thereof, nor any of their employees, makes any warranty, express or implied, or assumes any legal liability or responsibility for the accuracy, completeness, or usefulness of any information, apparatus, product, or process disclosed, or represents that its use would not infringe privately owned rights. Reference herein to any specific commercial product, process, or service by trade name, trademark, manufacturer, or otherwise does not necessarily constitute or imply its endorsement, recommendation, or favoring by the United States Government or any agency thereof. The views and opinions of authors expressed herein do not necessarily state or reflect those of the United States Government or any agency thereof. 


\section{PENTEK METAL COATING REMOVAL SYSTEM}

\section{TABLE OF CONTENTS}

SECTION 1 SUMMARY .......................... 1

Technology Description $\ldots \ldots \ldots \ldots \ldots \ldots \ldots \ldots \ldots \ldots \ldots \ldots \ldots$

Key Results ............................

SECTION 2 -TECHNOLOGY DESCRIPTION $\ldots \ldots \ldots \ldots \ldots \ldots \ldots \ldots \ldots$

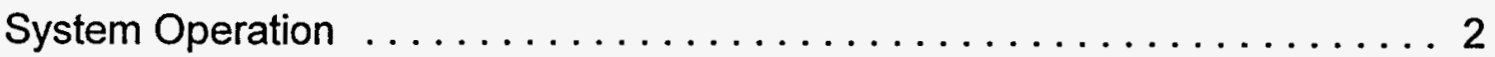

SECTION 3 - HEALTH AND SAFETY EVALUATION $\ldots \ldots \ldots \ldots \ldots \ldots \ldots$

General Health and Safety Concerns $\ldots \ldots \ldots \ldots \ldots \ldots \ldots \ldots$

Core Issues . . . . . . . . . . . . . . . . . . . . . . 3

Best Management Practices $\ldots \ldots \ldots \ldots \ldots \ldots \ldots \ldots \ldots \ldots \ldots \ldots$

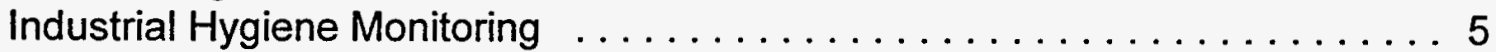

Human Factors Interface $\ldots \ldots \ldots \ldots \ldots \ldots \ldots \ldots \ldots \ldots$

Emergency Response/Preparedness .................8

SECTION 4 - TECHNOLOGY APPLICABILITY ................ 9

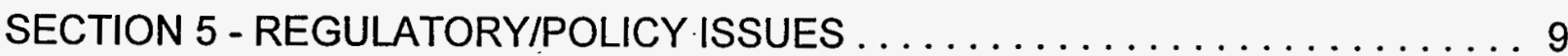

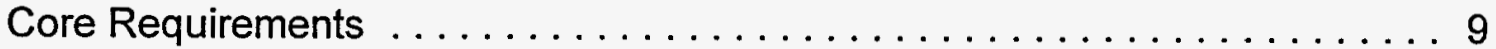

Special requirements . . . . . . . . . . . . . . . . . . . 10

Best Management Requirements $\ldots \ldots \ldots \ldots \ldots \ldots \ldots \ldots \ldots \ldots \ldots \ldots$

Core Training Requirements . . . . . . . . . . . . . . . . . . . 11

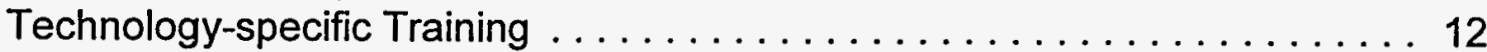

Special Training . . . . . . . . . . . . . . . . . . . . . . 12

Best Management Practices . . . . . . . . . . . . . . . . . 12

SECTION 6 - OPERATIONAL CONSIDERATIONS AND

RECOMMENDATIONS ..................... 12

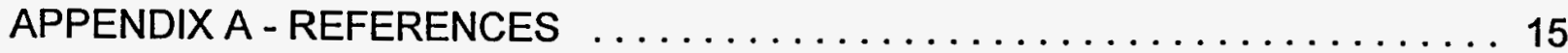

APPENDIX B - INDUSTRIAL HYGIENE DATA . . . . . . . . . . . . . 16 


\section{PENTEK METAL COATING REMOVAL SYSTEM (ROTO-PEEN SCALER, CORNER-CUTTER ${ }^{\circledR}$, VAC-PAC ${ }^{\circledR}$ \\ HUMAN FACTORS EVALUATION}

\section{SECTION 1 - SUMMARY}

\section{TECHNOLOGY DESCRIPTION}

The Pentek coating removal technology was tested and is being evaluated at Florida International University (FIU) as a baseline technology. In conjunction with FIU's evaluation of efficiency and cost, this report covers evaluation conducted for safety and health issues. It is a commercially available technology and has been used for various projects at locations throughout the country.

The Pentek coating removal system consisted of the ROTO-PEEN Scaler, CORNERCUTTER $^{\oplus}$, and VAC-PAC ${ }^{\circledR}$. They are designed to remove coatings from steel, concrete, brick, and wood. The Scaler uses $3 \mathrm{M}$ Roto Peen tungsten carbide cutters while the CORNER-CUTTER ${ }^{\circledast}$ uses solid needles for descaling activities. These hand tools are used with the VAC-PAC ${ }^{\circledR}$ vacuum system to capture dust and debris as removal of the coating takes place.

\section{KEY RESULTS}

The safety and health evaluation during the testing demonstration focused on two main areas of exposure: dust and noise. Dust exposure minimal, but noise exposure was significant. Further testing for each exposure is recommended because of the environment where the testing demonstration took place. It is feasible that the dust and noise levels will be higher in an enclosed operating environment of different construction. In addition, other areas of concern found were arm-hand vibration, whole-body vibration, ergonomics, heat stress, tripping hazards, electrical hazards, machine guarding, and lockout/tagout. 


\section{SECTION 2 \\ TECHNOLOGY DESCRIPTION}

\section{SYSTEM OPERATION}

The Pentek coating removal technology was tested and is being evaluated at Florida International University (FIU) as a baseline technology. In conjunction with FIU's evaluation of efficiency and cost, this report covers evaluation conducted for safety and health issues. It is a commercially available technology and has been used for various projects at locations throughout the country.

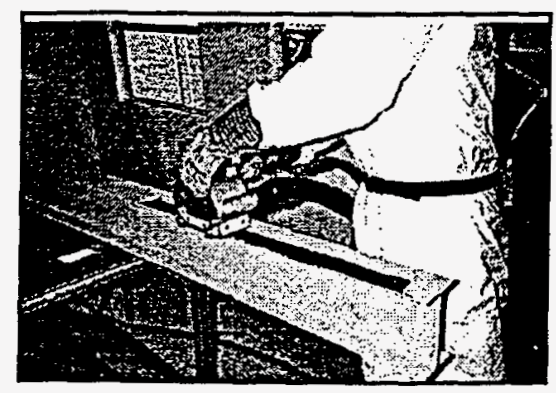

Figure 1- Roto peen scaler

The Pentek coating removal system consists of the ROTOPEEN Scaler, CORNER-CUTTER ${ }^{\circledR}$, and VAC-PAC ${ }^{\circledR}$. They are designed to remove coatings from steel, concrete, brick, and wood. The Scaler uses $3 \mathrm{M}$ Roto Peen tungsten carbide cutters while the CORNERCUTTER $^{\circledR}$ uses solid needles for descaling activities. These are used with the VAC-PAC ${ }^{\oplus}$ vacuum system to capture dust and debris as removal of the coating takes place.

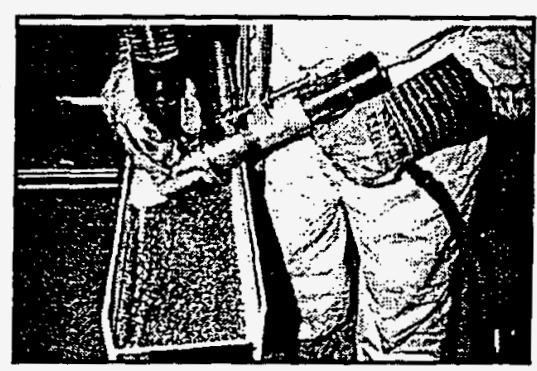

Figure 2 - Corner cutter

The VAC-PAC ${ }^{\oplus}$ is a vacuum system designed to be used with Pentek's surface decontamination equipment. Dust and debris are captured by the two-stage positive

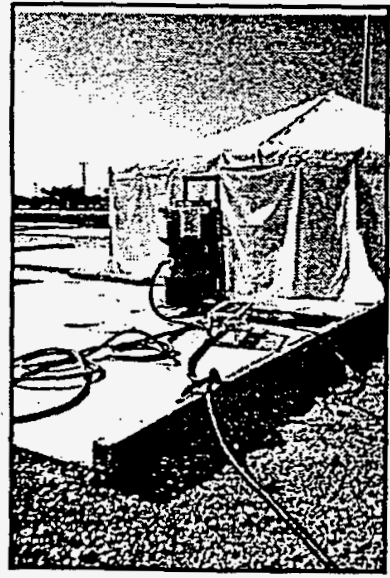

Figure 3 - Vac Pac filtration high efficiency particulate filter (HEPA) vacuum system that deposits the waste directly into an on-board 55-gallon or 23-gallon waste drum. The first stage filters have a $99.5 \%$ efficiency at 1 micron and a second stage HEPA efficiency of $99.97 \%$ at 0.3 microns. The first stage filters or roughing filters are continuously and automatically cleaned by reverse-flow pulses of high pressure air. The system is designed with high efficiency pneumatic eductors or electric vacuum generators. The system also has a fulldrum alarm, multiple nozzles for simultaneous operation of several hoses, and the capacity to operate with hoses up to 200 feet long.

The ROTO PEEN Scaler uses the $3 \mathrm{M}$ heavy duty roto peen tungsten carbide cutters. It is designed for flat areas and large vertical surfaces. The mechanical action of fracturing and removing coatings occurs within an evacuated enclosure where dust and 
debris are captured by the vacuum system described above. The scaler features speed adjustment, an adjustable handle with three distinct positions, a safety-lock throttle to prevent accidental start-up, and a $1 \frac{1}{2}$ inch vacuum port cuff.

The CORNER-CUTTER ${ }^{\otimes}$ is a pneumatically operated needle scaler that operates within an evacuated stainless steel enclosure to capture dust and debris using the vacuum system previously described. It is designed to use different shrouds which maintain contact with surfaces of differing shapes and sizes, and a quick-release-to-off safety feature.

The operator did not encounter difficulties with equipment operation while dressed out in the appropriate PPE. The technology did present an extreme noise hazard. These as well as other safety and health factors will be discussed in greater detail in other sections of this report.

The scalers left some water on the metal surface during operation. This could create a secondary contamination. This seemed to be caused by water in the air lines. Routine preventive maintenance must be an intrinsic part of the descaling process to prevent secondary contamination created by the technology itself. Additionally, the heat exchanger on the air compressor must be in the "on" position to avoid this problem.

\section{SECTION 3 \\ HEALTH AND SAFETY EVALUATION}

\section{GENERAL SAFETY AND HEALTH CONCERNS}

Personnel where the Pentek descaling technology is being used need to be concerned with safety and health issues. Issues that personnel need to be cognizant of may be divided into two categories. First, core issues are those that are based on current safety and health regulatory requirements. Second, best management practices are related to issues that are not based on current safety ad health regulations but are key elements in preventing worker injury and illness on the job. Safety and health issues of concern with the heavy duty roto peen technology included:

\section{CORE ISSUES:}

Tripping hazards - although necessary, the electrical cords, air lines, and vacuum hoses needed to operate the equipment are tripping hazards. Therefore, the need for stringent housekeeping must be evaluated.

- Pinch points - frequently the operator had to use hand placement as a method to control the equipment. This caused his hand to be in a position where the scaler could come into contact with his hand if the scaler slipped. Standard Operating Procedures (SOP's) should not allow the hands to be placed where they could 
come into contact with the operating end of the scaler. The scalers need to be evaluated for handles or other mechanisms that allow control of the equipment without placing the hands in a precarious position.

- Electrical hazards - electrical cords and sources necessary to operate the equipment can present electrical hazards, therefore, the need for ground fault circuit interrupters, grounding, and strain relief must be evaluated.

- Lockout/Tagout - the user of the technology will need to develop a lockout/tagout program to assure there is not an accidental release of energy during maintenance/repair activities. In addition, during operation the worker had to periodically reach under the evacuated enclosure on the ROTO PEEN scaler to clear the flaps - this has the potential to cause serious injury to the hand/fingers if the drum begins rotation while the hand/fingers are inserted. The operator should never reach under energized equipment. The scaler needs to be evaluated to correct this problem by engineering design.

- Noise - the user was subjected to an extreme amount of noise while operating the ROTO-PEEN and CORNER-CUTTER ${ }^{\circledast}$ scalers used during the testing demonstration.

- Dust - the equipment generated some visible dust during operation but dust was not evident in the breathing zone of the operator. Larger debris was left on the surface. The amount of dust generated in the breathing zone of the operator may change based on the environment in which the metal decontamination is taking place, therefore, the user of the technology will need to develop a sampling plan based on the individual site needs. It should also be noted that there was potential for contamination to dust when changing filters and during barrel change activities with the VAC-PAC ${ }^{\circledR}$.

When a diesel engine is used to operate ancillary equipment such as the air compressor, exposure to diesel fumes must also be taken into consideration.

\section{BEST MANAGEMENT PRACTICES:}

- Heat stress - the operator was subjected to an increase in heat stress due to the need to utilize PPE. The user will need to develop a heat stress program for the environment in which the technology is being used, taking into consideration any PPE that may need to be utilized.

- Ergonomics - the user was subjected to some ergonomic stressors that need to be taken into consideration such as, stooping, bending, twisting, kneeling, and lifting, and wrist, hand, arm, and shoulder stress and abnormal positioning. Of particular concern are the descalers which cause the wrist/arm/shoulder to be placed in 
awkward positions during operation. In addition, when full drums are being changed on the VAC-PAC ${ }^{\circledR}$, mechanical lifting devices need to be utilized.

- Arm-hand vibration - the user was subjected to excessive arm-hand vibration during operation of the ROTO-PEEN and CORNER-CUTTER ${ }^{\oplus}$ scalers. This type of vibration has the potential to lead to health problems such as Raynaud's Syndrome.

- Whole-body vibration - the descaling operation caused vibration of the floor in the area. This potential for exposure to whole-body vibration will need to be assessed on a job-by-job basis based on the physical environment where the job is taking place.

- Struck by hazards - the air lines have the potential to cause severe injury if their fittings fail. A safety line between the male and female end of the fittings would prohibit the line from becoming airborne.

- Communication - due to the noise generated by the technology during operation, communication could be difficult. Personnel working in the area should be knowledgeable of and proficient in the use of hand signals when needed.

\section{INDUSTRIAL HYGIENE MONITORING}

During the testing demonstration with the Pentek descaling system, sampling was conducted for dust and noise. In addition, the wet-bulb globe temperature was monitored to evaluate heat stress. Observational evaluation was conducted for ergonomics and armhand vibration.

Through general observational techniques the potential for ergonomic problems was evaluated during the testing demonstration. There is potential for muscle/back stress and/or injuries due to bending, twisting, and lifting associated with setup, operation, maintenance, and decontamination. There is potential for stress on and/or injury to the knees due to the kneeling and stooping required during setup, maintenance, and decontamination activities. There is potential for wrist, hand, arm, and shoulder injury due to the awkward positions required during operation of the descalers. This was evident by the operator's need to constantly change hand position while using the equipment.

During the testing demonstration exposure to arm-hand vibration was present during the operation of the ROTO-PEEN and CORNER-CUTTER ${ }^{\otimes}$ scalers. While arm-hand vibration was not quantitatively measured, it was readily apparent that there was exposure that could potentially cause health problems such as Raynaud's syndrome. Whole-body vibration was also present during operations due to the vibration of the floor in the area. 
Heat stress was monitored using a Quest QuestTemp 15 Heat Stress Monitor. The wetbulb globe temperature was used to determine the work/rest regimen in accordance with the American Conference of Governmental Industrial Hygienist (ACGIH) recommendations. The wet-bulb globe temperature was adjusted for the type of clothing, including PPE, that the worker was wearing.

In addition, the worker's blood pressure, pulse, and temperature were monitored throughout the day. No problems were encountered due to heat stress but the worker's comfort level was increased when not wearing the PPE. While heat stress will be increased while wearing PPE, the overall heat stress response will vary from worker to worker. Each situation in which the current technology is used will need to be evaluated for the heat stress potential taking into consideration the wet-bulb globe temperature, PPE in use, physical condition of the worker, and amount of worker acclimatization.

Dust monitoring was conducted with a sampling train consisting of an SKC IOM. Inhalable dust sampler coupled with a MSA Escort Elf air sampling pump. Pre- and post-sampling calibration was accomplished using a BIOS International DryCal DC1 primary calibration system. Sampling filters were desiccated pre- and post-sampling and weighed on a Denver Instrument Company A-200DS scale. Sampling was conducted in accordance with $\mathrm{NIOSH}$ method 0500.

Personal sampling was conducted on the equipment operators during descaling operations. Personal dust sampling results of $0.3247 \mathrm{mg} / \mathrm{m}^{3}$ and $0.0 \mathrm{mg} / \mathrm{m}^{3}$ were obtained for Operator Number 1 and results of $1.0417 \mathrm{mg} / \mathrm{m}^{3}$ and $0.0 \mathrm{mg} / \mathrm{m}^{3}$ were obtained for Operator Number 2. These values do not exceed the Occupational Safety and Health Administration (OSHA) permissible exposure limit (PEL) or the ACGIH threshold limit value (TLV) of $15 \mathrm{mg} / \mathrm{m}^{3}$ and $10 \mathrm{mg} / \mathrm{m}^{3}$ respectively for total dust. There was however, larger pieces of debris left on the surfaces being descaled. This condition could potentially become airborne and therefore, become an inhalation hazard. Due to this and the dust sampling being conducted in an enclosure with open windows, it is recommended that sampling be conducted while the descaling operation is being conducted in a closed environment. A complete air sampling plan for a site would need to be developed to include not only dust but other contaminants specific to the metal decontamination project. (See Appendix B for sampling data.)

Personal noise monitoring was conducted using Metrosonic db-3100 data logging noise dosimeters. Calibration was conducted pre- and post-monitoring using a Metrosonics CL304 acoustical calibrator. Monitoring was conducted on Operator Number 1 for $2.03^{\circ}$ hours (122 minutes), 0.95 hours (57 minutes), and 3.15 hours (189 minutes) during operation of the descaling system. Monitoring during this time showed a noise dose of $961.22 \%$, which gives an 8-hour time-weighted average (TWA) of $106.3 \mathrm{dBA}, 226.26 \%$, which gives an 8-hour TWA of $97.0 \mathrm{dBA}$, and $849.47 \%$, which gives an 8-hour TWA of $105.4 \mathrm{dBA}$. If Operator Number 1 continued to have the same level of noise exposure during the 8-hour shift a projected 8-hour TWA would produce a noise dose of $3664.78 \%$, 
or an 8-hour TWA of $115.98 \mathrm{dBA}, 2269.52 \%$, or an 8-hour TWA of $112.5 \mathrm{dBA}$, and $2152.31 \%$, or an 8-hour TWA of $112.1 \mathrm{dBA}$.

Monitoring on Operator Number 2 was conducted for 2.38 hours ( 143 minutes), 1.85 hours (111 minutes), and 4.06 hours (244 minutes) during operation of the descaling system. Monitoring showed a noise dose of $115.78 \%$, which gives an 8-hour TWA of $107.4 \mathrm{dBA}$; $460.11 \%$, which gives an 8-hour TWA of $101.0 \mathrm{dBA}$; and $1281.96 \%$, which gives an 8-hour TWA of $108.4 \mathrm{dBA}$. If Operator Number 2 continued to have the same level of noise exposure during the 8-hour shift, a projected 8-hour TWA would produce a noise dose of $3969.39 \%$, or an 8-hour TWA of $116.5 \mathrm{dBA}$; 1986.21\%, or an 8-hour TWA of $111.6 \mathrm{dBA}$; and $2522.09 \%$, or an 8-hour TWA of $113.3 \mathrm{dBA}$.

The OSHA allowable PEL for noise is a $100 \%$ dose or an 8 -hour TWA of $90 \mathrm{dBA}$. Operator Number 1 and 2 were overexposed after all times (assuming the operator had no other noise exposure during the work shift). At these exposure levels, personnel would be required to be included in a hearing conservation program. Feasible engineering controls, administrative controls, and personal protective equipment (PPE-hearing protection devices) need to be used. If you take the highest projected 8-hour exposure TWA which was $116.5 \mathrm{dBA}$ and assume the use of a hearing protection device with the highest noise reduction rating (per the NIOSH Compendium of hearing protection devices) was being used, the worker would theoretically still be overexposed for an 8-hour shift. The excessive noise levels produced by the descaling operation may require that engineering and administrative controls as well as hearing protection devices all be simultaneously employed to control the noise level. The percentage of time spent at each loudness level that comprises the exposures can be seen in Appendix B.

During the different periods of operation for Operator Number 1, the noise levels were averaged for each one minute period of time and then an overall average of each one minute period was calculated and gave an average exposure level of $115.9 \mathrm{dBA}$ for an 80 $\mathrm{dB}$ and $90 \mathrm{~dB}$ cutoff level, $112.5 \mathrm{dBA}$ for an $80 \mathrm{~dB}$ and $90 \mathrm{~dB}$ cutoff level, and $112.1 \mathrm{~dB}$ for an $80 \mathrm{~dB}$ and a $90 \mathrm{~dB}$ cutoff level. The average exposure level for Operator Number 2 was $116.5 \mathrm{dBA}$ for an $80 \mathrm{db}$ and a $90 \mathrm{~dB}$ cutoff level, $111.5 \mathrm{dBA}$ for an $80 \mathrm{~dB}$ and a 90 $\mathrm{dB}$ cutoff level, and $113.2 \mathrm{~dB}$ for an $80 \mathrm{~dB}$ and a $90 \mathrm{~dB}$ cutoff level. OSHA requires an 80 $\mathrm{db}$ cutoff for hearing conservation measurements and a $90 \mathrm{db}$ cutoff for engineering controls compliance measurements. The maximum sound levels observed during the measurement period were 126.2 dBA, 132.3 dBA, and 128.2 dBA for Operator Number 1 and $125.2 \mathrm{dBA}, 133.4 \mathrm{dBA}$, and $128.3 \mathrm{dBA}$ for Operator Number 2. The highest instantaneous sound pressure levels were $137.7 \mathrm{~dB}, 132.3 \mathrm{~dB}$, and $141.4 \mathrm{~dB}$ for Operator Number 1 and $137.9 \mathrm{~dB}, 133.4 \mathrm{~dB}$, and $141.1 \mathrm{~dB}$ for Operator Number 2.

These measurements define noise as an extreme exposure for personnel operating the Pentek descaling system using the ROTO-PEEN Scaler and CORNER-CUTTER ${ }^{\circledR}$. It must also be noted that the equipment was being operated in a wooden-walled and floored structure at the time of the measurements and operation in a facility of different construction will have the potential to increase the noise level due to other influences such 
as vibration and reverberation. Therefore, it is recommended that noise monitoring be conducted while the equipment is being operated in environments of differing types of construction.

\section{HUMAN FACTORS INTERFACE}

The equipment operators were dressed out in Level C PPE which included a Tyvek suit with hood, work gloves, boot coverings, and full face air-purifying respirator. The only difficulty the operator had operating the equipment while wearing Level C PPE was some visibility problems due to the full face respirator. In addition, the need to perform work in the Level $\mathrm{C}$ ensemble caused some increase in heat stress for the operator.

If the metal being decontaminated had contamination other than or in addition to dust, additional levels of protection, such as Level A or Level B PPE, may be required for the operator. These may create additional human interface problems such as a greater decrease in visibility and manual dexterity, an increase in heat stress, and an overall increase in physical stress. It is recommended that additional safety and health evaluations be conducted utilizing these higher levels of protection.

Additional human factors interface issues concerned the amount of arm-hand vibration the operator was receiving during operation of the ROTO-PEEN Scaler and CORNERCUTTER ${ }^{\circledast}$. It is recommend that further evaluation with quantitative measurements of arm-hand vibration be conducted for this equipment.

\section{EMERGENCY RESPONSE/PREPAREDNESS}

The use of the Pentek metal descaling technology would not be applicable to emergency response.

Emergency response/preparedness must be part of every hazardous waste site safety and health plan. In addition to credible site emergencies, site personnel must plan for credible emergencies in connection with the

All precautions used when responding to an emergency situation at the site will apply. Before entering an area where the ROTO-PEEN Scaler, CORNER-CUTTER ${ }^{\circledR}$, and VAC-PAC ${ }^{\otimes}$ are being used, the equipment needs to be completely shut down (deenergized).

This technology does not appear to present any conditions that would lead to out-ofthe-ordinary emergencies. 


\section{SECTION 4 \\ TECHNOLOGY APPLICABILITY}

On observation the technology did not generate visible dust into the atmosphere and air monitoring did not show a significant dust Level But this was difficult to assess due to the open windows in the testing environment. There were larger pieces of debris left on the surface during descaling. The system needs to be evaluated to determine if an increase in vacuum air flow would help with this problem.

The ROTO-PEEN Scaler, CORNER-CUTTER ${ }^{\oplus}$, and VAC-PAC ${ }^{\circledR}$ will need to be torn down to decontaminate them. This will not necessarily guarantee that decontamination will be complete.

According to the technology representative, many parts, such as the hoses, roto peens, and needles may be considered consumables. In addition, the roughing filters can be removed directly into a bag and disposed of, thereby helping to eliminate additional worker exposure to contamination.

\section{SECTION 5 REGULATORYIPOLICY ISSUES}

The site safety and health personnel where the Pentek metal descaling technology is being used need to be concerned with safety and health regulations applicable to the issues discussed above. Regulations that apply may be divided into four categories. First, core requirements are those regulations that would apply to any hazardous waste work site, regardless of the type of job. Second, technology specific requirements are those regulations that apply due to the specific technology being used. Third, special requirements are standards and policies that are specific to the technology itself but are required by reference in a regulation. Fourth, best management practices are not required but are recommended by organizations such as the American National Standards Institute (ANSI), the National Institute of Occupational Health and Safety (NIOSH), Department of Energy (DOE), National Fire Protection Association (NAPA), etc. These regulations/standards may include but not be limited to the following:

CORE REQUIREMENTS:

- OSHA 29 CFR 1926.25 Housekeeping

OSHA 29 CFR 1910.141 Sanitation (1910.141(a)(3) covers housekeeping)

OSHA 29 CFR 1926 subpart Z Toxic and Hazardous Substances 
- OSHA 29 CFR 1910 Subpart Z Toxic and Hazardous Substances

- OSHA 29 CFR 1926.59 Hazard Communication

- OSHA 29 CFR 1910.1200 Hazard Communication

- OSHA 29 CFR 1926.64 Process Safety Management of Highly Hazardous Chemicals

- OSHA 29 CFR 1910.119 Process Safety Management of Highly Hazardous Chemicals

- OSHA 29 CFR 1926.65 Hazardous Waste Operations and Emergency Response

- OSHA 29 CFR 1910.120 Hazardous Waste Operations and Emergency Response

- Occupational Safety and Health Act 1970(5)(a)(1) General Duty Clause

\section{TECHNOLOGY SPECIFIC REQUIREMENTS:}

- OSHA 29 CFR 1926 Subpart K Electrical

- OSHA 29 CFR 1910 Subpart S Electrical

- OSHA 29 CFR 1926 Subpart I Tools-Hand and Power

- OSHA 29 CFR 1910 Subpart P Hand and Portable Powered Tools and Other Hand-Held Equipment

- OSHA 29 CFR 1910 Subpart O Machinery and Machine Guarding

- OSHA 29 CFR 1910.147 The Control of Hazardous Energy (Lockout/Tagout)

- OSHA 29 CFR 1926.52 Occupational Noise Exposure

- OSHA 29 CFR 1910.95 Occupational Noise Exposure

$+\quad$ OSHA 29 CFR 1926.103 Respiratory Protection

$+\quad$ OSHA 29 CFR 1910.134 Respiratory Protection 
$-\quad$ OSHA 29 CFR 1926.102 Eye and Face Protection

- OSHA 29 CFR 1910.133 Eye and Face Protection

- OSHA 29 CFR 1926.28 Personal Protective Equipment

- OSHA 29 CFR 1910.132 General Requirements (Personal Protective Equipment)

- OSHA 29 CFR 1926.23 First Aid and Medical Attention

- OSHA 29 CFR 1910.151 Medical Services and First Aid

- ACGIH Threshold Limit Values for Chemical Substances and Physical Agents and Biological Exposure Indices

\section{BEST MANAGEMENT PRACTICES:}

- ANSI S3.34-1986 Guide for the Measurement and Evaluation of Human Exposure to Vibration Transmitted to the Hand

- ANSI S3.18-1979 Guide for the Evaluation of Human Exposure to Whole-body Vibration

In addition to the above regulations and policies, it is imperative that all workers have appropriate and adequate training for the task and associated safety and health conditions. Training that would be required may be divided into four categories. Core training is that which is required for anyone entering a hazardous waste site to perform work, regardless of the type of job. Technology specific training is that training that is specific to the technology and required by safety and health standards. Special training is that which is specific to the technology to assure the worker is adequately trained for the task but is not necessarily required by safety and health standards. Best management practices are trainings that while not mandated by health and safety standards, provide information and knowledge to the worker that will allow the worker to perform his/her job safely. Training to be applied for the heavy duty roto peen may include but not be limited to:

\section{Core Training Requirements:}

HAZWOPER (Hazardous Waste Operations and Emergency Response)

- HAZCOM (Hazard Communication) 


\section{Technology Specific Training:}

- Respiratory Protection

- Hearing Conservation

- Personal Protective Equipment

- Electrical Safety

Lockout/Tagout

\section{Special Training:}

- Job specific training for equipment operation

\section{Best Management Practice Training:}

- Ergonomics (proper lifting, bending, stooping, kneeling, arm-hand vibration, whole-body vibration)

- Heat stress (learning to recognize signs and symptoms)

- CPR/First Aid/Emergency Response/Blood borne Pathogens

- Hand Signal Communication

- Construction Safety (OSHA 500) and or General Industry Safety (OSHA 501)

\section{SECTION 6}

\section{OPERATIONAL CONSIDERATIONS \& RECOMMENDATIONS}

Recommendations made here for improved worker safety and health take into consideration the operation of the ROTO-PEEN Scaler, CORNER-CUTTER ${ }^{\circledR}$, and VAC$P A C^{\circledR}$. Specific recommendations include:

- It needs to be assured that workers are aware of the tripping hazards associated with hoses and cords that are necessary to operate the equipment. Keeping these as orderly as possible in compliance with good housekeeping regulations will help avoid injury due to tripping.

- The vacuum hoses were not connected to the outlet on the pieces of equipment by means of a clamping system and at times were duct taped. This could allow 
the hoses to be pulled loose and create an exposure to the contaminant. Hoses should be attached with some type of clamping system to reduce the possibility that they will become detached accidentally.

- The operators of the equipment need to have training in ergonomics to assure proper techniques in lifting, bending, stooping, twisting, etc. during equipment operation. In addition, training needs to include discussion on ergonomics associated with the wrists/hands, arms, and shoulders when using hand tools. The tools themselves need to be evaluated for ergonomic design to enable the worker to use them without having to place themselves in awkward positions. For example, the worker often used the vacuum hose connection and the top of the housing of the ROTO PEEN scaler to move and control the machine but did not use the handle. A better handle design such as making the handle easy to move would allow the worker to move it to the required position.

- Water from the air lines was dripping onto the metal surface. This causes a secondary contamination. The heat exchanger on the air compressor must be in the "on" position to avoid this problem.

- If a fitting on an air line fails, the flying hose has the potential to cause severe injury. A safety line connected to the male and female Parts of the fitting would not allow the hose to become a flying object.

- The control gauges located on the VAC-PAC ${ }^{\circledR}$ such as the roughing filter gauge were often difficult to see from a distance. A duplication of these gauges in the area where the job was being conducted would enable the operator to react to them in a more timely manner. Additionally, some of the numerical ranges for the needle gauges were not adequate. For example, on the rough filter gauge, the range was $0-5$. The needle may peg but there is no indication of the degree of problem beyond that. It is suggested that the range be made wider and also color coding be used for better visibility and redundancy for making the operator aware that there is a potential problem.

- When changing out a full drum the operator must use the controls on the VAC$\mathrm{PAC}^{\circledast}$. They are difficult to reach (the operator is stooping and must reach above shoulder and head height) when using a 23-gallon drum and they are used blindly since the operator cannot look at the gauges and the drum/drum seal at the same time. Moving the controls to a position where they are easy to access and visible to the operator during drum change is recommended.

- A full 23-gallon drum may weight 220 pounds or more and a 55-gallon even more. This presents great potential for back injury when two operators lift the drum for change out. It is recommended that the system be evaluated for use with a mechanical for lifting system. 
- During rough filter changing, the dirty filters are removed into a plastic bag and disposed of. The operator had some difficulty with tactile sensation working with gloves through the bag. It is recommended that glove bags be considered for use. This would allow the operator greater dexterity and still provide for containment of the contamination during removal. In addition the bag was held in place by duct tape. It is recommended that some type of hooks be used to hold the bag in place instead.

When changing out a full drum, a cardboard disk is used as a barrier between the drum and filter unit. This disk was held in place by the vacuum suction. If there is a loss in vacuum pressure during change out the disk will fall and there is an increase in the potential for exposure to the contaminant. It is recommended that a system such as hooks be designed to hold the disk in place in the event that vacuum pressure would be lost.

- To set the frequency of cleaning (blow back) on the roughing filters, the operator had to open the front panel of the VAC-PAC ${ }^{\oplus}$. This would cause contamination to the inside of the panel. It is recommended that a mechanism that allows this adjustment to made be placed on the outside of the panel.

- Noise exposure was extreme during operation of the technology. Since testing was done in a wooden structure, it is plausible that the noise levels would increase in an environment of different construction. The equipment needs to be evaluated for possible engineering controls to help decrease the noise exposure to the operator. If engineering controls are not possible, administrative controls, and/or adequate hearing protection must be incorporated during operation.

Due to the open window environment in which the testing demonstration was conducted and therefore, the dust monitoring was conducted, it is recommended that further testing for dust exposure be conducted while the technology is used in a closed environment similar to environments in which it would be used at a hazardous waste clean-up site. Due to the wooden structure in which the testing demonstration took place, and therefore, the noise monitoring was conducted, it is recommended that noise monitoring be conducted while the technology is used inside environment of different construction. There could be a difference in noise levels due to the construction of the building. This would also allow for an evaluation of the heat stress to be encountered while wearing the appropriate PPE in different environments.

It is also recommended that the operation and maintenance activities be evaluated while the operator is wearing Level A and Level B PPE since these levels may be needed in environments where the contamination requires it.

The safety and health issues discussed throughout this report could be reduced and in some cases eliminated if this type of descaling technology could operate remotely. 


\section{APPENDIX A REFERENCES}

Occupational Safety and Health Standards for General Industry, 29 CFR Part 1910, Occupational Safety and Health Administration United States Department of Labor, 1995

Occupational Safety and Health Standards for the Construction Industry, 29 CFR Part 1926, Occupational Safety and Health Administration United States Department of Labor, 1995

Threshold Limit Values (TLV's) for Chemical Substances and Physical Agents and Biological Exposure Indices (BEl's), American Conference of Governmental Industrial Hygienists, 1995-1996

ANSI 1986, Guide for the measurement and evaluation of human exposure to vibration transmitted to the hand, New York, NY: American National Standards Institute, ANSI S3.34

The NIOSH compendium of hearing protection devices, U.S. Department of Health and Human Services, Public Health Service, Center for Disease Control and Prevention, October 1994 


\section{APPENDIX B \\ IH SAMPLING DATA}

\begin{tabular}{|c|c|c|c|}
\hline \multicolumn{4}{|c|}{ 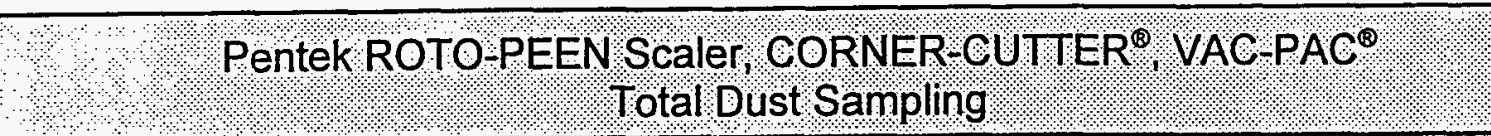 } \\
\hline arte & Sarigie Nunber & arables & Restils \\
\hline $5 / 9 / 79$ & 050996-FIU-010 & Blank & $0.0000 \mathrm{mg} / \mathrm{m}^{3}$ \\
\hline $5 / 9 / 96$ & 050996-FIU-011 & Total dust & $0.3247 \mathrm{mg} / \mathrm{m}^{3}$ \\
\hline $5 / 9 / 96$ & 050996-FIU-012 & Total dust & $1.0417 \mathrm{mg} / \mathrm{m}^{3}$ \\
\hline $5 / 9 / 96$ & 050996-FIU-013 & Blank & $0.0000 \mathrm{mg} / \mathrm{m}^{3}$ \\
\hline $5 / 9 / 96$ & 050996-FIU-014 & Total dust & $0.0000 \mathrm{mg} / \mathrm{m}^{3}$ \\
\hline $5 / 9 / 96$ & 050996-FIU-015 & Total dust & $0.0000 \mathrm{mg} / \mathrm{m}^{3}$ \\
\hline
\end{tabular}

* The OSHA PEL for total dust is $15 \mathrm{mg} / \mathrm{m}^{3}$ and the ACGIH TLV is $10 \mathrm{mg} / \mathrm{m} 3$. Current sampling was conducted for total dust. The need to sample for respirable dust and silica has to be considered during concrete decontamination and decommissioning activities. 


\section{NOISE SAMPLING}

Amplitude Distribution Data

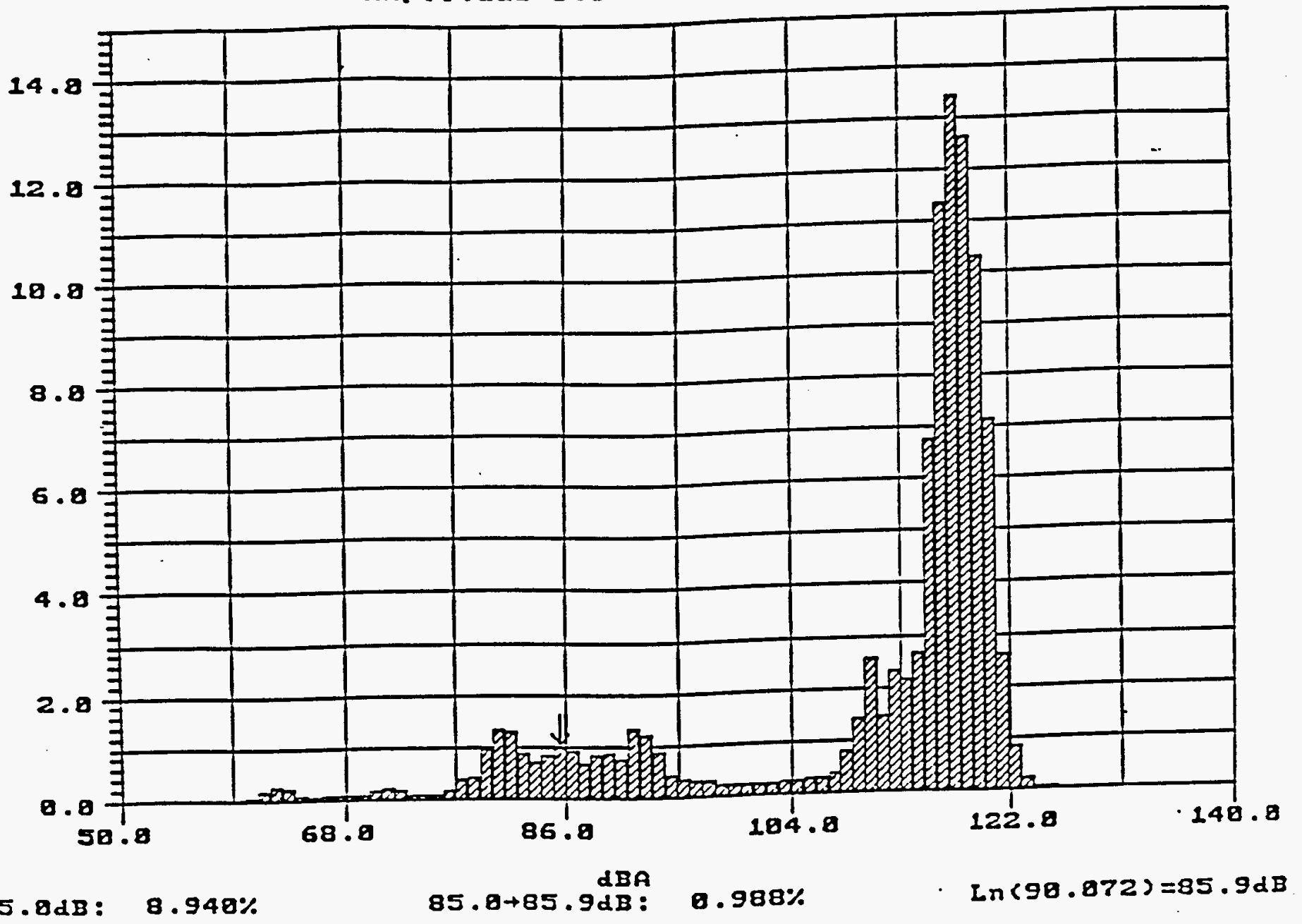

The percentage of time spent at each decibel level can be obtained from the graph. As shown, $8.940 \%$ of the time the noise exposure was less than $85 \mathrm{dBA}$ which means that the majority of the time or $91.06 \%$ of the time the noise exposure was at sound levels above $85 \mathrm{dBA}$. OSHA requires that a hearing conservation program be initiated if the 8 -hour TWA is $85 \mathrm{dBA}$. 


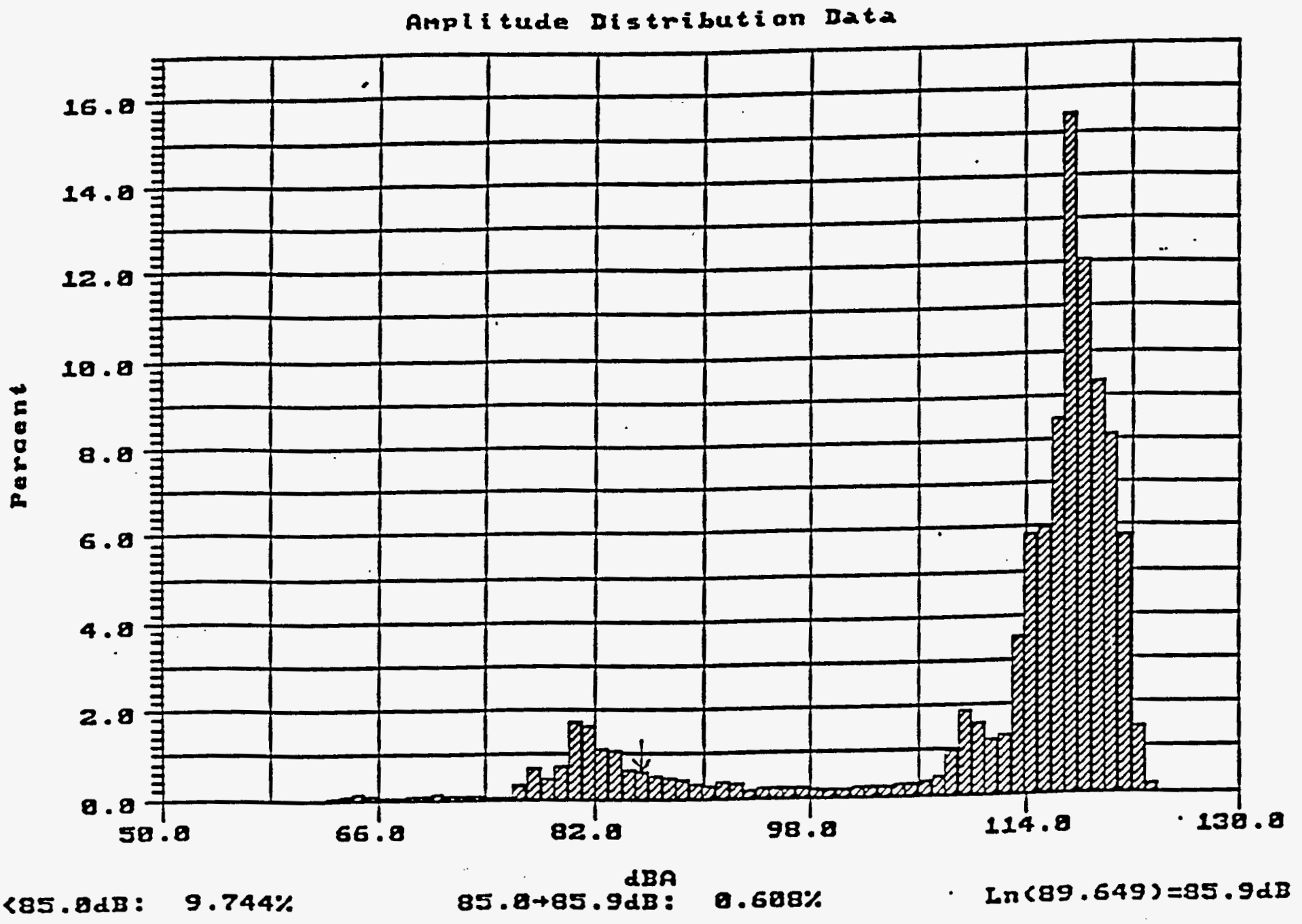

The percentage of time spent at each decibel level can be obtained from the graph. As shown, $9.744 \%$ of the time the noise exposure was less than $85 \mathrm{dBA}$ which means that the majority of the time or 90.256 if the time the noise exposure was at sound levels above $85 \mathrm{dBA}$. OSHA requires that a hearing conservation program be initiated if the 8-hour TWA is $85 \mathrm{dBA}$. 


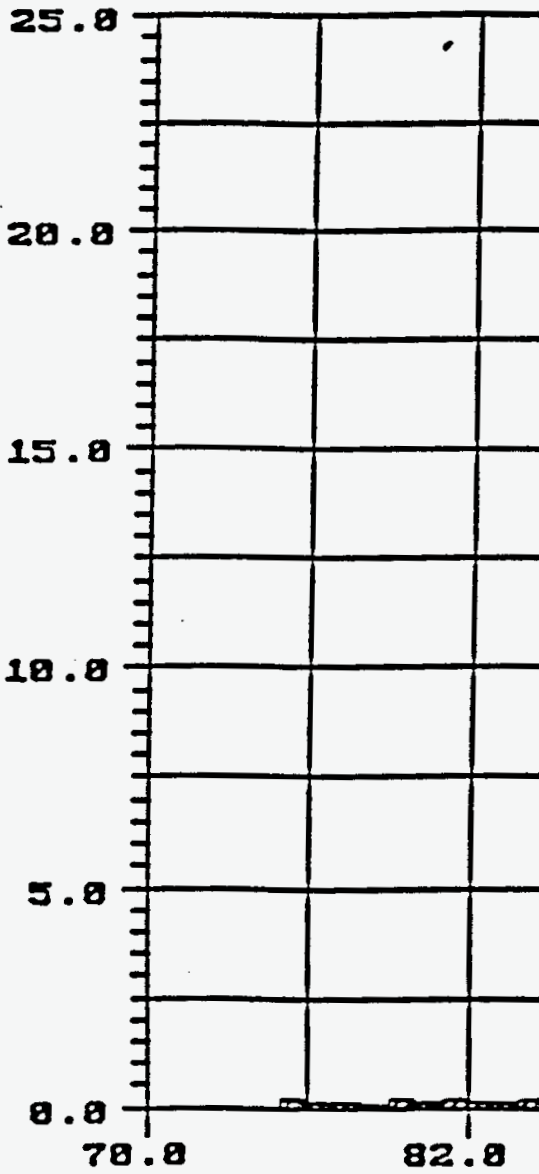

Amplitude Distribution Data

78.8

82.8

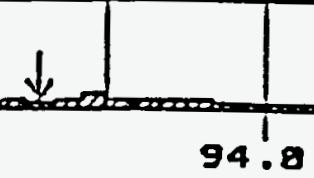

dBA

C85.8dB: $1.613 \%$

$85.8+85.9 d B:$

0. $154 \%$

$\ln (98 \cdot 233)=95.9 \mathrm{~dB}$

The percentage of time spent at each decibel level can be obtained from the graph. As shown, $1.613 \%$ of the time the noise exposure was less than $85 \mathrm{dBA}$ which means that the majority of the time or $98.387 \%$ of the time the noise exposure was at sound levels above $85 \mathrm{dBA}$. OSHA requires that a hearing conservation program be initiated if the 8-hour TWA is $85 \mathrm{dBA}$. 
Amplitude Distribution Data

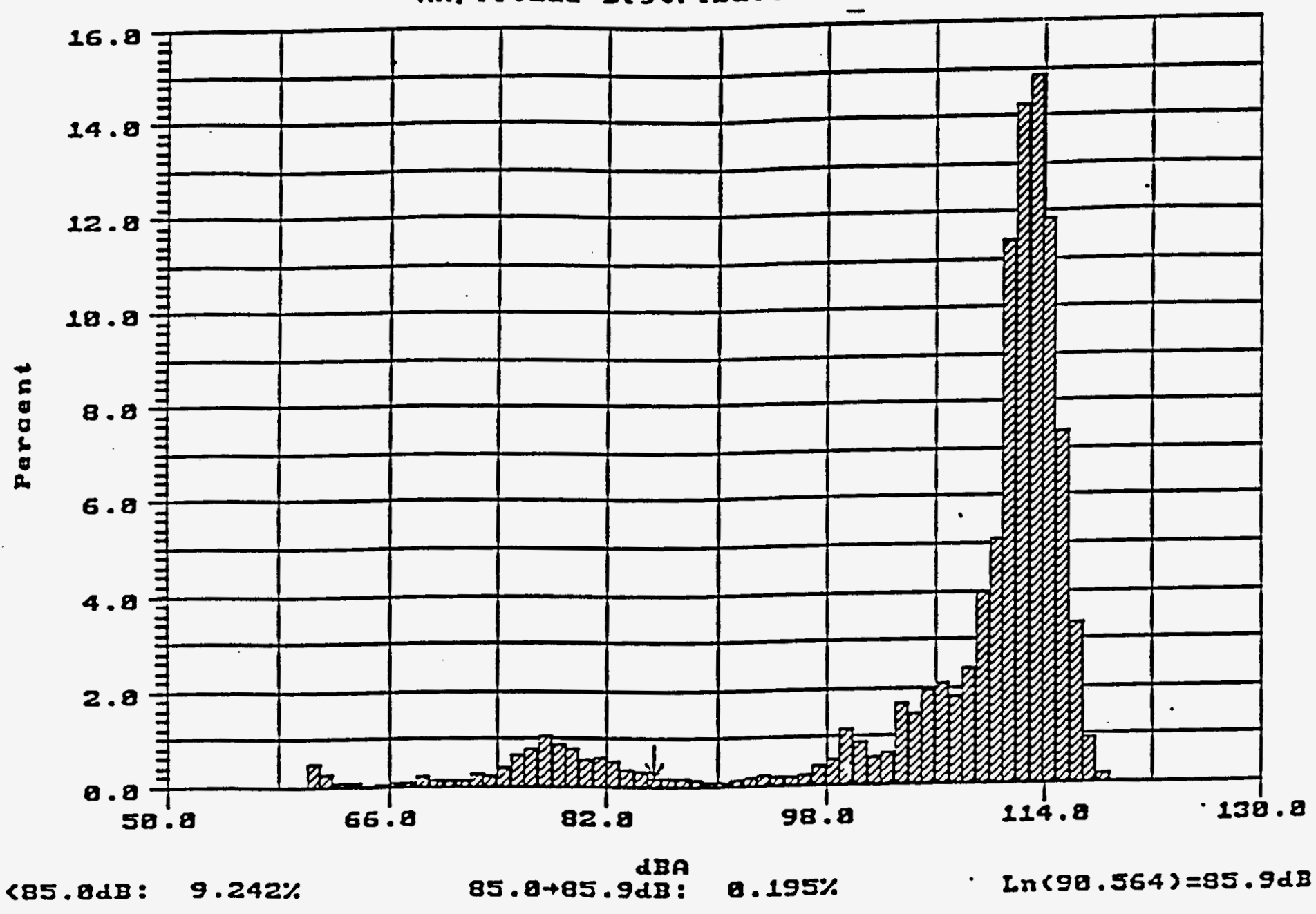

The percentage of time spent at each decibel level can be obtained from the graph. As shown, $9.242 \%$ of the time the noise exposure was less than $85 \mathrm{dBA}$ which means that the majority of the time or $90.758 \%$ of the time the noise exposure was at sound levels above $85 \mathrm{dBA}$. OSHA requires that a hearing conservation program be initiated if the 8-hour TWA is $85 \mathrm{dBA}$. 


\section{NOISE SAMPLING}



The percentage of time spent at each decibel level can be obtained from the graph. As shown, $20.141 \%$ of the time the noise exposure was less than $85 \mathrm{dBA}$ which means that the majority of the time or $79.859 \%$ of the time the noise exposure was at sound levels above $85 \mathrm{dBA}$. OSHA requires that a hearing conservation program be initiated if the 8-hour TWA is 85 dBA. 
Amplitude Distribution Data

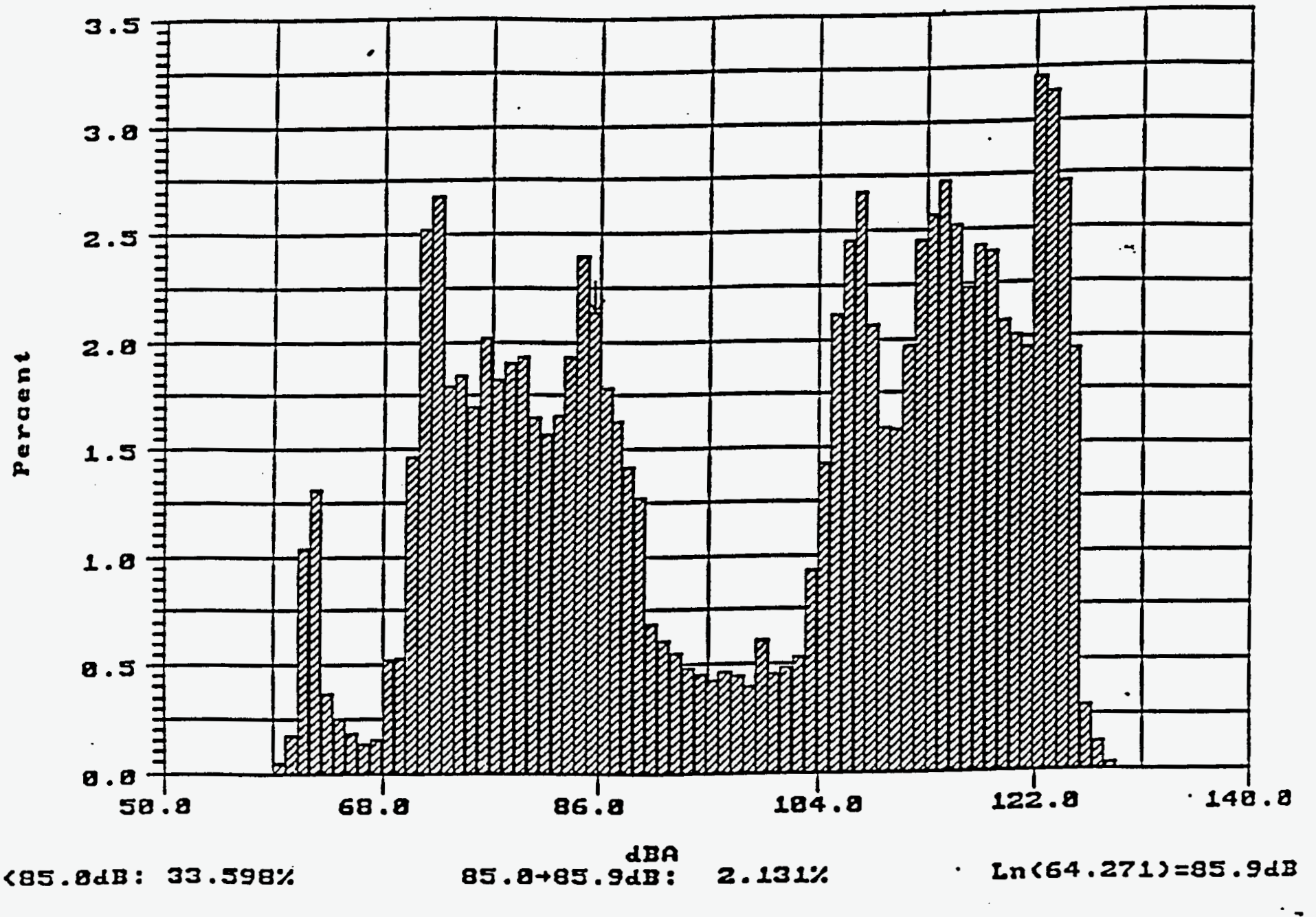

The percentage of time spent at each decibel level can be obtained from the graph. As shown, $33.598 \%$ of the time the noise exposure was less than $85 \mathrm{dBA}$ which means that the majority of the time or $66.402 \%$ of the time the noise exposure was at sound levels above $85 \mathrm{dBA}$. OSHA requires that a hearing conservation program be initiated if the 8-hour TWA is $85 \mathrm{dBA}$. 
Report Number (14) DoE/mc/32260--5847

Jubl. Date (11)

11) $\frac{19970731}{\Delta 0 \varepsilon / \varepsilon m ; \Delta 0 \varepsilon / F \varepsilon, X F}$

Sponsor Code

JC Category (19) UC-2000; UC-101, DOE/ER 